\title{
eCOti
DiAno
}

Revista Mídia e Cotidiano

ISSN: 2178-602X

Editorial

Volume 14, Número 2, maio-ago. de 2020

\section{Jornalismo e Literatura: paradigmas e novas dlimensões}

\section{Journalism and Literature: paradigms and new dimensions}

\author{
Rachel BERTOL ${ }^{1}$ e Frederico de Mello B. TAVARES ${ }^{2}$
}

A Revista Mídia e Cotidiano, ao acolher nesta edição o dossiê Jornalismo e Literatura, lida com uma questão complexa, que precede, inclusive, a institucionalização dos estudos comunicacionais na segunda metade do século passado. As relações possíveis de se estabelecer entre o jornalismo e literatura são de ordem tão antiga que abordar essa interseção nos leva facilmente a um imaginário de mídias de papel - tinteiros, manuscritos, tipografias, impressos, máquina de escrever... Depois de tanto, e no mundo digitalizado, não ofende perguntar: ainda há o que se falar a respeito? O conjunto de oito textos selecionados para o dossiê (dos cerca de 30 submetidos) fornece caminhos e pistas para se renovarem as respostas a respeito. Além disso, o processo de realização do dossiê permitiu aos editores uma visão panorâmica sobre como as duas áreas buscam se aproximar dessa relação. Concluímos o trabalho com novas perguntas e convencidos de que há benefícios mútuos quando ambas buscam se pôr em conjunção uma com a outra.

$\mathrm{Na}$ entrevista que realizamos para esta edição com Geraldine Rogers, da Universidade Nacional de La Plata, na Argentina, que dialoga com o dossiê, a pesquisadora destaca que há zonas de contato e transferência com a literatura e que esta não deixa de estabelecer com o jornalismo - seu espelho invertido e discurso dominante

\footnotetext{
${ }^{1}$ Professora adjunta do Departamento de Comunicação Social da Universidade Federal Fluminense e professora e pesquisadora do Programa de Pós-Graduação em Mídia e Cotidiano. É Doutora em Comunicação e Cultura (UFRJ), com período sanduíche na Universidade de Princeton (EUA). É líder do grupo de pesquisa Tempos: Temporalidade dos Meios Comunicacionais, Linguagem e Cotidiano (UFF/CNPq) e participa dos grupos de pesquisa Imprensa e Circulação de Ideias: o papel dos periódicos nos séculos XIX e XX, da Casa de Rui Barbosa, e do Mídia, Memória e Temporalidade (Memento), da UFRJ. E-mail: rachelbertol@id.uff.br. ORCID: 0000-0001-8411-4002.

2 Professor adjunto na Universidade Federal de Ouro Preto (UFOP), onde atua no curso de Graduação em Jornalismo e no Programa de Pós-Graduação em Comunicação (PPGCOM). Doutor em Ciências da Comunicação (Unisinos) e um dos líderes do GIRO - Grupo de Pesquisa em Mídia e Interações Sociais (UFOP/CNPq, Brasil). Realizou o Pós-doutorado junto à Universidad Nacional de La Plata (UNLP, Argentina) em 2019-2020. E-mail: fredmbtavares@ gmail.com. ORCID: 0000-0001-6410-4739.
} 




da modernidade, como disse - relações de oposição e concorrência. Muitas vezes, isso explicaria, inclusive, a transformação das poéticas. No caso do jornalismo, de onde partimos para realizar nossos questionamentos, trata-se de aprofundar e ampliar o escopo das abordagens teóricas (o que se reflete na prática), que se referem a seu potencial crítico e criativo e, nesse sentido, também à maneira como a área fala de si, ou seja, como se reconhece e justifica sua pertinência diante da sociedade.

Esse movimento mais amplo ocorre porque, ao nos situarmos na interseção entre duas áreas - no limiar entre uma e outra - , somos inevitavelmente convocados a questionar suas fronteiras. Assim, somos levados a ponderar quais os melhores caminhos para cruzarmos os lados e, se for o caso, aproximá-los.

É preciso destacar que uma das principais vertentes que a área do jornalismo recorre para se aproximar da literatura é a do chamado jornalismo literário ou narrativo (a nomenclatura é variada, segundo a perspectiva teórica, mas possui de alguma maneira a mesma base). Inspirado em práticas norte-americanas, o jornalismo literário se consolidou no século XX, mesmo século em que se assistiu ao aprofundamento da chamada profissionalização da prática jornalística. Trata-se, desse modo, também de uma especialização que se preocupa (de maneira geral) em depurar a escrita jornalística e sugere práticas de apuração mais elaboradas e com maior dedicação em relação àquelas do dia a dia da profissão. O jornalismo, afinal, é uma prática cotidiana: no jornalismo literário, encontraríamos alguma possibilidade de suspensão desse cotidiano (uma pausa quem sabe necessária para retornar ao cotidiano com novos olhares, ampliando seus horizontes). Há muito o que se investigar nessa corrente. Entretanto, numa época em que as especializações, tal como se configuraram no século XX, encontram-se em reinvenção (caso da identidade jornalística), não seria proveitoso ampliar o repertório de pontos de contato com a literatura? Ou, quem sabe: implodir a ideia dessa especialização e desdomesticar o "literário" como uma funcionalidade para o jornalismo?

O primeiro artigo do dossiê, intitulado "Narrar, viver: a legitimação do testemunho nas narrativas jornalística e literária”, de José Eduardo Mendonça Umbelino Filho e Marcelo Ferraz de Paula, enfrenta questões difíceis nesse debate, como as dicotomias - que o texto indica muitas vezes como falseadoras - que se costuma realizar entre ficção e não ficção. O texto problematiza a noção de objetividade, trazendo 


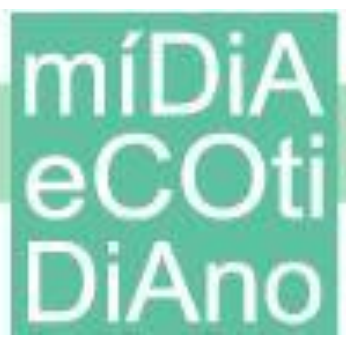

elementos para discutir a voz jornalística como testemunho. Também aborda o vocabulário corrente dos meios de comunicação - como fake news e pós-verdade - que circundam o debate do senso-comum sobre a legitimidade da voz jornalística. Portanto, trata-se de questões amplas que se coloca; não nos encontramos, assim, na redoma da especialização. Fazer a travessia - sair do jornalístico, cruzar seu limiar - seria importante para contrapor teorias: olhar somente para as teorias jornalísticas já estabelecidas talvez não ajude a ir além da perspectiva estabelecida no século $\mathrm{XX}$, insuficiente diante dos desafios contemporâneos.

$\mathrm{O}$ artigo "A personagem no jornalismo narrativo: empatia e ética", de Marcio Serelle, parte de teorias desenvolvidas sobre a personagem na ficção - que, segundo o autor, são mais desenvolvidas que no jornalismo - para discutir as características de sua construção no jornalismo narrativo (esta a terminologia que usa). A personagem é uma figura plástica que transita por diferentes mídias - onde couberem histórias, nos jornais, nos livros, no teatro, nos meios audiovisuais. Com diferentes aportes, o autor discute o limite ético que circunda as personagens (notadamente as anônimas) nessa corrente do jornalismo que ele considera tributária do realismo. Em "Por carreteras secundárias: reflexões sobre o reporterismo a partir da narrativa de Bru Rovira sobre a cotidianidade dos anônimos", de Mauro de Souza Ventura e Tayane Aidar Abib, é apresentada a obra do jornalista catalão, discutida pelo prisma da noção de "reporterismo" desenvolvida pelo colombiano Raúl Hernando Osorio Vargas e de teorias do jornalismo literário no Brasil. Um dos objetivos é mostrar como o jornalista, pela escolha de temas "secundários" na grande mídia e pela maneira como os retrata (especialmente as figuras anônimas), constrói uma frente de contra-hegemonia em suas reportagens, reiterando a potência desse tipo de escrita.

A relação com o jornalismo e a obra do escritor português José Saramago, em diferentes perspectivas, é o tema de "Documentar, ir a campo e narrar: aproximações técnicas e diálogos críticos entre Saramago e o jornalismo", de Maria do Socorro Furtado Veloso e Henrique Alberto Mendes. O texto mostra como o escritor de alguma maneira traz para sua escrita técnicas de apuração, assim como documenta com notícias a composição de algumas obras. Trata-se assim de observar como o jornalismo contribui e, ao mesmo tempo, aprende - com o escopo de uma obra literária ética. 
Outro autor que inspirou artigos foi João Guimarães Rosa, a partir de diferentes pontos de interseção com o jornalismo. Um dos artigos selecionados a seu respeito é “Grande sertão: veredas e 'Sertão grande': escrita e (re)significação na interface entre literatura e jornalismo", de Daniela Martins Barbosa Couto e Rita Aparecida da Conceição Ribeiro. O artigo analisa a série de reportagens Sertão Grande, publicada na editoria de Economia do jornal Estado de Minas, que se baseia no romance de Rosa. Destaca-se a "zona de contato" dessa interface, na viagem empreendida e na escrita, em que se cria um interdiscurso entre fato e ficção, do qual emerge um sertão de carências. Já em "Crítica do silêncio temático em Grande Sertão: veredas - uma leitura de Diadorim", de Gustavo de Castro e Leandro Bessa, o foco é o conservadorismo da crítica literária em jornal, que seria avessa a abordar temas de gênero e de abjeção na obra. Essa postura crítica também nos informaria sobre o estado do jornalismo brasileiro?

Os dois últimos textos selecionados se voltam para a crônica. Um deles, "A crônica mundana e a circulação transnacional de modelos narrativos”, de Orna Messer Levin e Heloísa Leite Imada, trata da crônica em pespectiva histórica, tendo como foco a belle époque e a relação da imprensa brasileira com a francesa. $\mathrm{O}$ texto que fecha a seção temática, por sua vez, tem foco regional e aborda as cronistas mulheres da Paraíba, de Maryellen Bãdãrãu e Sandra Raquew Azevêdo. O dossiê se completa, portanto, apontando para relações entre literatura e jornalismo que, no caso deste, vão além do debate somente sobre a reportagem. O jornalismo comporta muitas possibilidades de escrita, que hoje (talvez ainda mais que há algumas décadas) precisam ser retomadas com vigor na cena teórica.

Já a Seção Livre desta edição da Revista Mídia e Cotidiano, a segunda de 2020, inicia com o artigo "Experiências da extensão universitária para a cultura e formação cidadã", que busca problematizar o espaço da extensão como um lugar de reflexão e de experiências urgentes do exercício de cidadania e do desenvolvimento do compromisso social, como intrínsecos à formação na graduação. Trata-se do um projeto desenvolvido na Unipampa, sul do país, onde a presença da universidade pública tem significado maior acesso à cultura e à arte e integração com a comunidade. Deste universo que talvez ainda não seja tão valorizado como devesse, isto é a teoria e prática extensionista, passamos, 
com os três próximos artigos, à centralidade da internet no cenário midiático contemporâneo.

O primeiro destes textos é "Internet das Coisas: um olhar para o consumidor das Gerações Y e Z e para a nova concepção do tempo", que traz como questão central o que o título explicita, ou seja, a relação que um determinado grupo de jovens constitui com a chamada "internet das coisas". Em seguida, com "Shun de Andrômeda e as correntes das masculinidades: gênero, jornalismo de cultura pop e construção de sentidos em redes digitais", problematiza-se as disputas de sentido que têm ocorrido, quase sempre de modo bastante intempestivo, neste espaço virtual, como também ocorre, mas em outra chave, em "O adolescente em conflito com a lei na pauta de dois sites de Campo Grande, MS", que procura demarcar o papel que o jornalismo online tem cumprido na corroboração de um imaginário nada positivo em relação ao jovem. Finalmente, fechando a seção, temos o artigo "Espetáculo à mesa: midiatização da cozinha nos reality shows de gastronomia", cujo objetivo é discutir o processo de espetacularização da cozinha desde que esta passou a ocupar um espaço intenso e extenso na televisão, ressignificando, portanto o próprio ato de comer e de cozinhar.

Uma boa leitura a todos!

Rachel Bertol e Fred Tavares (Editores da Seção Temática) Andrea Medrado, Denise Tavares e Isabella Rega (Editoras-chefes) 